\title{
Japan's austere 1987 budget ignores inflation
}

\section{Tokyo}

THE most austere budget in 32 years has been proposed for Japan in fiscal year 1987. The draft budget, approved by the cabinet, has been frozen at last year's level. Nevertheless, some large increases have been won for certain sectors of science and technology. The nuances of the financial package will be formally debated in the Diet in the next two months.

Despite a ballooning trade surplus, Japan is in debt to the tune of $\$ 1$ million million. And this year, as in the past several years, funding for the ministries has been drastically cut, except the Defense Agency which will enjoy a healthy boost in funding of more than 5 per cent.

The completion of some projects and cuts in funding for energy-related research have allowed the launching of new projects in the science-based ministries. The budget for the Science and Technology Agency, as in previous years, shows an increasing commitment to basic research as well as "big science" (such as space and nuclear power). "Frontier Research", a 10 -year international basic research programme to investigate homeostasis and develop "frontier materials" (for example, biochips) gets a massive boost. The Ministry of International Trade and Industry (MITI) has also more than doubled its funding for biochip research in its programme "basic technology for future industries", and several large electronics companies are showing interest in this field of the future.

The completion of the MOS- 1 marine observation satellite, due to be launched next month, has released large amounts of funds for development of the engineering test satellite ETS-VI, due for launch in 1992. The $\mathrm{H}-2$ rocket also gets a huge infusion of funds, taking up nearly a third of the agency's space budget. There is also a 50 per cent increase in outlay for Japan's module for the US space station.

The large increase in ocean research funding is to cover the costs of building the new deep-sea submersible Shinkai 6500 and its mother ship. Similarly, the large outlay for marine science in the budget for the Ministry of Education, Science and Culture is to cover building a new research vessel for the Ocean Research Institute at the University of Tokyo.

In line with the Education Reform Council's recommendation to "internationalize" the education system, the ministry has increased the number of foreign students it supports with scholarships to well over 4,000 . The target for the 21 st century is a foreign student population of 100,000 , with 10,000 supported by scholarships.

Since the early 1980 s, the ministry has been trying to increase cooperation in re-

search between the public and private sector with small success (although the funds involved are minuscule compared with the research and development outlays of industry as a whole). To encourage coopera-

\section{Japanese science budget}

Science and

Technology Agency

Total research and

development budget

Special promotion

funds

Space

Nuclear energy

Ocean research

ERATO

Frontier research

$\begin{array}{rr}\begin{array}{c}\text { Yen } \\ \text { (thousand } \\ \text { million) }\end{array} & \begin{array}{r}\text { Percentage } \\ \text { increase or } \\ \text { decrease }\end{array} \\ 432.5 & +1.1 \\ & \\ 8.5 & +8.7 \\ 94.6 & +2.1 \\ 273.4 & -0.7 \\ 7.7 & +16.2 \\ 3.2 & +17.5 \\ 1.5 & +37.2\end{array}$

Ministry of Education,

Science and Culture

Grants-in-aid of

research

Maintenance of scientific

research system

Research fellowships

Energy

(Nuclear fusion)

(New energy sources,

energy conservation)

Accelerator physics

(TRISTAN)

Space science

Marine science

Earth science

Antarctic research

Cancer research

International academic

exchange

International student

exchange

Japanese language

education

45.1

\section{0}

1.1

13.4

(7.6)

(5.7)

13.2

12.9

11.8

11.8
3.0

2.1

2.9

1.8

3.6

14.5

0.3

$+3.7$

$+17.2$

$+49.5$

$-10.2$

$(-7.0)$

$(-14.0)$

$(-0.9)$

$-4.4$

$+470.8$

$+0.5$

$-5.5$

$+4.8$

$+3.7$

$+23.9$

$+8.3$

Ministry of International

Trade and Industry

Total technology

development budget

Basic technology research

promotion centre

Basic technology for

future industries

Large-scale industrial

projects

Sunshine project

Moonlight project

Fifth generation

computer project

Unmanned space

platform

Laser enrichment of

uranium

Proving tests for technology for fast

breeder reactors

Human frontiers

science programme

* Includes Y150 million from the special promotion funds of the Science and Technology Agency tion and direct research towards the practical needs of society, "joint research centres" will be set up in some universities, and the first three will open in 1987 at Kobe, Toyama and Kumamoto universities with funding for "maintenance of the scientific research system". Funds from this category are also being used to establish an "International Center for the Study of Japanese Culture" in Kyoto, which will be a National Research Institute for joint university use.

Although there is a decrease in outlay for nuclear fusion, the ministry is still committed to moving Nagoya University's Institute of Plasma Physics to a new site in Gifu Prefecture (see Nature 320, 204; 1986), and the last parcel of land for this will be bought and levelled this year.

The education ministry's Institute of Space and Astronautical Sciences (ISAS) has won approval for its plan to launch the Solar-A satellite in 1991 to observe solar flare activity with two X-ray telescopes to be developed jointly with US scientsts (see Nature 322, 762; 1986). And, according to Minoru Oda, director of ISAS, UK space scientists will also join the project.

ISAS is also involved in plans to develop an unmanned space platform in collaboration with the Science and Technology Agency and MITI; MITI's budget for the platform this year has increased tenfold to Y1,700 million. The platform, to be launched in 1992, probably by an H2 rocket, will perform engineering tests (for example solar power generation) and may carry a medium-sized infrared telescope.

MITI has raised Y8,300 million to begin development of techniques for the laser enrichment of uranium and to carry out proving tests of components of fast breeder reactors. Japan was caught by surprise in 1985 when the United States announced its intention to adopt the laser method, but MITI and the Science and Technology Agency now have well-funded programmes for the technique.

Two hundred million yen has been set aside by MITI and the Science and Technology Agency to launch the Human Frontiers Science Program, a major international research project in basic bioscience. Scientists from Europe and the United States have been invited to Japan to discuss the programme with ministry officials and academics. MITI's plan calls for the establishment of a non-profit foundation which will accept funds from the Japanese government, industry and abroad. The foundation will then channel funds to the "Center for the Promotion of the Human Frontier Science Program", which will disburse grants to participating researchers, universities and institutes, in Japan and overseas. David Swinbanks 